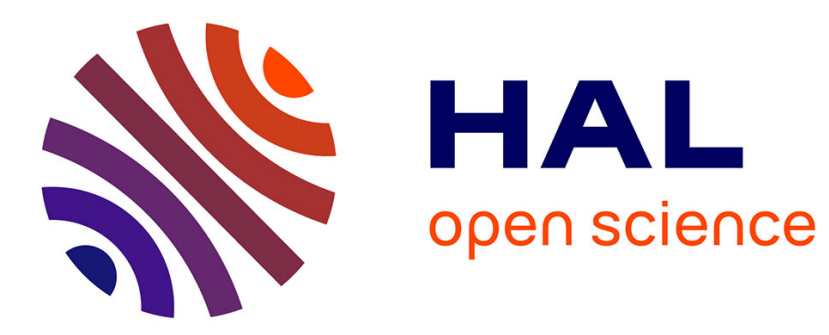

\title{
In vivo human PSC-derived intestinal organoids to study stem cell maintenance
}

Vales Simon, Poling Holly, Sundaram Nambirajan, Michael A Helmrath, Maxime Mahé

\section{> To cite this version:}

Vales Simon, Poling Holly, Sundaram Nambirajan, Michael A Helmrath, Maxime Mahé. In vivo human PSC-derived intestinal organoids to study stem cell maintenance. Intestinal Stem Cells, Epub ahead of print, inPress. inserm- 02578852

\section{HAL Id: inserm-02578852 https://www.hal.inserm.fr/inserm-02578852}

Submitted on 14 May 2020

HAL is a multi-disciplinary open access archive for the deposit and dissemination of scientific research documents, whether they are published or not. The documents may come from teaching and research institutions in France or abroad, or from public or private research centers.
L'archive ouverte pluridisciplinaire HAL, est destinée au dépôt et à la diffusion de documents scientifiques de niveau recherche, publiés ou non, émanant des établissements d'enseignement et de recherche français ou étrangers, des laboratoires publics ou privés. 
In vivo human PSC-derived intestinal organoids to study stem cell maintenance.

Vales Simon ${ }^{1}$, Poling Holly M. ${ }^{1}$, Sundaram Nambirajan ${ }^{1}$, Helmrath Michael A. ${ }^{1,2}$, Mahe Maxime M. ${ }^{1,2,3^{*}}$.

${ }^{1}$ Department of Pediatric General and Thoracic Surgery, Cincinnati Children's Hospital Medical Center, Cincinnati, Ohio, USA;

${ }^{2}$ Department of Pediatrics, University of Cincinnati, Cincinnati, Ohio;

${ }^{3}$ UMR Inserm 1235 - TENS, INSERM, Université de Nantes, Institut des Maladies de 1'Appareil Digestif - CHU de Nantes. 1 Rue Gaston Veil, 44035 Nantes Cedex 1, France.

*Corresponding author:

Maxime M. Mahe: maxime.mahe@inserm.fr

Running title: Stem cells in human intestinal organoids.

Summary:

Human intestinal organoids (HIOs), derived from pluripotent stem cells, are a new tool to gain insights in gastrointestinal development, physiology and associated diseases. Herein, we present a method for orthotopic renal transplantation of HIOs in immunocompromised mice and subsequent analysis to study intestinal epithelial proliferation. In addition, we describe how to generate enteroids from transplanted HIOs. The method highlights the specific steps to successful engraftment and provides insight into the study of human intestinal stem cells.

Keywords:

Human intestinal organoids, Pluripotent stem cells, Transplantation, in vivo model, Intestinal stem cell, Enteroid. 
1. Introduction.

The intestinal tract is lined by a simple columnar epithelium shaped into finger-like protrusions called villi and surrounded by multiple invaginations or crypts. The intestinal epithelium is one the fastest renewing tissues in humans ${ }^{1}$. The constant epithelial regeneration is driven by active intestinal stem cells (ISCs) located at the bottom of the crypts $^{2}$. ISCs divide to produce fast-proliferative progenitor cells also called transit amplifying cells (TA cells). TA cells undergo additional cell divisions as they migrate toward the tip of the villi. These cells will ultimately give rise to either secretory (enteroendocrine, Paneth and Goblet cells) or absorptive (enterocytes, colonocytes) lineages that will contribute to the mature epithelium ${ }^{3}$.

In the last decade, intestinal organoid models have been developed to study ISCs maintenance and differentiation ${ }^{4}$. Methods based on pluripotent stem cell-directed differentiation have allowed the generation of human intestinal organoids (HIOs) ${ }^{5}$. Using a stepwise differentiation process that mimics embryonic intestinal development, human pluripotent stem cells (hPSC) can be differentiated into definitive endoderm and then into hindgut spheres that will form tridimensional intestinal structures. After 28 days in culture, HIOs present a polarized epithelium surrounded by supporting mesenchymal cells. In addition, in vivo engraftment of HIOs further both tissue expansion and maturation. Transplanted HIOs (tHIO) develop into an intestinal tissue that includes an epithelium containing all main differentiated intestinal cell lineages (enterocytes, goblet cells, Paneth cells, tuft cells and enteroendocrine cells) and a laminated mesenchyme forming submucosal and muscle layers ${ }^{6}$.

This model system provides us with a way to study ISC and progenitor cells in a fully developed and mature tissue of human origin. Herein, we describe a method to transplant 
hPSC-derived intestinal organoids under the kidney capsule in addition to intestinal cell proliferation and crypt-derived organoid formation assays.

2. Materials.

2.1 Human Intestinal Organoid (HIO) maintenance.

All solutions should be prepared fresh using sterile cell culture grade reagents.

1. Human intestinal organoids derived from human pluripotent stem cell lines.

2. Matrigel ${ }^{\circledR}$ Growth Factor Reduced; Phenol red-free.

3. Intestinal growth medium: Advanced DMEM/F12 medium supplemented with $2 \mathrm{mM}$ glutamine, $10 \mathrm{mM}$ HEPES, $100 \mathrm{U} / \mathrm{mL}$ penicillin, $100 \mu \mathrm{g} / \mathrm{mL}$ streptomycin, 1x N2 supplement, 1x B27 supplement and filter sterilized with $0.22-\mu \mathrm{m}$ filter (see Note 1).

4. Human recombinant Epidermal Growth Factor (EGF) (10,000x stock; $500 \mathrm{mg} / \mathrm{ml}$ in sterile PBS/0.1\% Bovine Serum Albumin).

2.2 Murine recipients, surgical equipment and reagents.

Aseptic technique is essential for any survival surgery and requires that all surgical instruments and supplies be sterile. All surgical instruments should be washed and sterilized in an autoclave prior to use. All surgeries are performed under a HEPA-filtered laminar flow bioBubble to prevent microbial contamination of the surgical site.

1. Mice: Female or Male immunocompromised NSG mice, NOD-scid IL2Rgamma ${ }^{\text {null }}$ are housed in microisolator systems in a barrier facility. The mice are used between 6 to 14 weeks 
of age (see Note 2).

2. Antibiotic diet: a modified chow diet (PicoLab Rodent Diet 20; LabDiet, St. Louis, MO, USA) is supplemented with 275 ppm Sulfamethoxazole and 1365 ppm Trimethoprim (LabDiet) (see Note 3).

5. Antibacterial drugs: $100 \mathrm{mg} / \mathrm{kg}$ of piperacillin and tazobactam are diluted in sterile saline solution and used for any surgeries (ZOSYN®; Pfizer, New York, NY, USA).

6. Buprenorphine.

7. Surgical Instruments: Suture tying forceps, Ring forceps, Dissecting scissors, BishopHarmon forceps, Halsey needle holder, Sterilization tray, Vannas spring scissors.

8. Isoflurane and anesthesia system (see Note 4).

9. Sterile 4-0 coated absorbable suture (VICRYL RAPIDE ${ }^{\mathrm{TM}}$; Ethicon, Cincinnati, OH, USA).

10. Sterile $18 \mathrm{G}$ blunt fill needles.

2.3 Thymidine analogues injection, sample preparation and staining.

1. $\mathrm{Ca}^{2+}$ and $\mathrm{Mg}^{2+}$ free Phosphate buffered saline (PBS), $\mathrm{pH}$ 7.2-7.6.

2. PBT solution: $0.5 \%$ Triton-X100 is diluted in PBS.

3. Blocking solution: 10\% normal donkey serum and 1\% Bovine Serum Albumin (BSA), Fraction V, are diluted in PBS.

4. Mounting medium: 70\% glycerol diluted in PBS (see Note 5).

5. Ethanol solutions: 70, 75, 85, 90, 95 and 100\% histology grade ethanol (v/v) diluted in Milli-Q - purified water.

6. 5-ethynyl-2'-deoxyuridine (EdU) solution: EdU powder (\#A10044, Thermo Scientific) is diluted at $10 \mathrm{mg} / \mathrm{mL}$ in sterile PBS (see Note 6).

7. $4 \%$ paraformaldehyde. 
8. HistoPrep Xylene (\#HC7001GAL, Fisher Scientific).

9. Deionized water.

10. Click-iT EdU Alexa Fluor 488 Imaging Kit (\#C10337, Thermo Scientific).

11. Citrate Buffer (pH 6).

12. Antibody diluent: $1 \%$ BSA is diluted in PBS.

13. Antibodies and fluorescent counterstain (see Table I).

14. Tissue Processor.

15. Embedding workstation stocked with paraffin.

16. Hybridization oven or equivalent.

17. Orbital shaker.

18. Tissue flotation bath.

19. Microtome and blades.

20. Slide staining set, including slide holders and chemical resistant reagent buckets.

21. Square bioassay dishes, as humidity chamber.

22. Tissue processing embedding cassettes.

23. Disposable base molds.

24. $1 \mathrm{~mL}$ TB syringe with $27 \mathrm{G} \mathrm{x} 1 / 2$ needle.

$25.75 \times 25 \times 1 \mathrm{~mm}$ positively charged microscope slides.

26. $24 \times 50 \mathrm{~mm}$, No. 1.5 Thickness glass cover slips.

27. Hydrophobic PAP pen.

28. Paper towels.

\begin{tabular}{|c|c|c|c|c|c|}
\cline { 2 - 6 } \multicolumn{1}{c|}{} & Antigen & Dilution & Host & Company & $\begin{array}{c}\text { Catalog } \\
\text { number }\end{array}$ \\
\hline \multirow{2}{*}{ Primary } & MKI67 & $1: 500$ & Rabbit & Thermo Scientific & RM9106 \\
\cline { 2 - 6 } & CDH1 & $1: 500$ & Mouse & BD Biosciences & 610182 \\
\hline Secondary & anti-rabbit & $1: 1000$ & Donkey & Thermo Scientific & A21206 \\
\hline
\end{tabular}




\begin{tabular}{|c|c|c|c|c|c|}
\hline & anti-mouse & $1: 1000$ & Donkey & Thermo Scientific & A10037 \\
\hline DAPI & Nuclei & & & Thermo Scientific & D1306 \\
\hline
\end{tabular}

Table I: List of primary and secondary antibodies used for immunofluorescence staining.

2.4 HIO-derived epithelial organoid generation and culture.

1. Dulbecco's phosphate buffered saline (DPBS).

2. Chelation buffer: $1 \%$ sorbitol, $1 \%$ sucrose, $1 \%$ bovine serum albumin fraction $\mathrm{V}(\mathrm{BSA})$ and 1x Gentamicin/Amphotericin solution are diluted in DPBS and filter-sterilized with a $0.22-\mu \mathrm{m}$ filter.

3. Ethylenediaminetetraacetic acid (EDTA) $0.5 \mathrm{M}$ diluted in ultrapure water.

4. Matrigel ${ }^{\circledR}$ Growth Factor Reduced; Phenol red-free.

5. Y-27623 compound diluted at $10 \mathrm{mM}$ (Stock solution) in sterile ultrapure water.

6. Intesticult ${ }^{\circledR}$ Human Organoid Growth medium (StemCell Technologies) (see Note 7).

7. Inverted tissue culture stereoscope.

8. Petri dishes.

9. Razor blades.

10. Minutien pins.

11. Dissecting microscope.

12. Silicone-coated glass Petri.

13. Small scissors.

14. Curved and fine forceps.

15. Micropipettes and micropipette tips.

16. Orbital shaker. 
17. $15 \mathrm{~mL}$ polypropylene conical tubes.

18. $150 \mu \mathrm{m}$ nylon mesh.

19. Centrifuge.

20. 24-well tissue-culture treated plates.

21. Cell culture incubator at $37^{\circ} \mathrm{C}, 5 \% \mathrm{CO}_{2}$.

3. Methodology.

3.1 Human Intestinal Organoids generation and maintenance.

The generation of Human Intestinal Organoids (HIOs) from pluripotent stem cells has been described in the following protocols ${ }^{7,8}$.

1. Culture HIOs in Matrigel ${ }^{\circledR}$ on a 24 -well plate in a $37^{\circ} \mathrm{C}, 5 \% \mathrm{CO}_{2}$ incubator.

2. Overlay HIOs with $500 \mu \mathrm{L}$ of intestinal growth medium supplemented with $50 \mathrm{ng} / \mathrm{mL}$ of human recombinant EGF (1:10 000 dilution of $500 \mu \mathrm{g} / \mathrm{mL}$ stock).

3. Change intestinal growth media supplemented with $50 \mathrm{ng} / \mathrm{mL}$ of human recombinant EGF every 4 days (see Note 8 ).

4. Bring the HIOs plate in the surgical room at the day of transplantation (see Note 9).

3.2. renal subcapsular transplantation of Human Intestinal Organoids.

A comprehensive method for the transplantation of HIOs into both the mesentery and kidney capsule of immunocompromised mice has been previously described ${ }^{9}$. In this section, we 
briefly outline the renal transplantation methodology, as it is the basis for subsequent analysis of the stem cell compartment, which will be examined in this chapter.

Proper surgical technique must be practiced, that is, asepsis, gentle tissue handling, minimal dissection of tissue, appropriate use of instruments, effective hemostasis, and correct use of suture materials and patterns. The person performing the procedures must be appropriately trained and working under a mentor or veterinarian to perform the procedure. During a surgical procedure, the person performing the procedures must wear clean scrubs, sterile surgical gown, mask, cap, and sterile gloves. Sterile surgical gown and gloves must be donned and maintained in an aseptic manner. All NSG mice are maintained on regular chow supplemented with antibiotics prior to transplantation.

1. Bring the mice to the operating suite where weighting and assessment of health status are performed.

2. Anesthetize the mouse in an anesthetic gases vaporizer delivering an Isoflurane $/ \mathrm{O}_{2}$ mixture (see Note 10).

3. Shave the left flank of the abdomen between the last rib and the iliac crest, and the spine and the lower third of the abdominal wall. Remove loose fur (see Note 11).

4. Prepare the surgical site using providine-iodine with a cotton-swab. Repeat the procedure with new cotton swabs three times.

5. Repeat the procedure using 70\% isopropyl alcohol with cotton-swabs. Repeat the procedures with new cotton swabs three times.

6. Place ophthalmic ointment on the eyes to prevent drying of the cornea and administer Buprenorphine $(0.05 \mathrm{mg} / \mathrm{kg})$ subcutaneously (see Note 12$)$.

7. Restrain the mouse on lateral recumbency, left kidney facing upward, and secure the mouse 
to a nosecone vaporizing Isoflurane/ $\mathrm{O}_{2}$ mixture (see Note 13 ).

8. Monitor respiratory rate and effort, along with the surgical plane of anesthesia. Confirm the loss of pedal reflex by pinching the toe with forceps.

9. Use straight forceps and fine scissors to make an 8-10 mm left posterior subcostal skin incision just below the last rib.

10. Use fine scissors to make a subsequent $8-10 \mathrm{~mm}$ retroperitoneal muscle incision.

11. Identify automatically the kidney using ring forceps and mobilize it into the wound.

12. Stabilize the kidney in the wound by placing a 7-0 silk suture loop with an untied square knot around the incision. Secure one ear of the suture with a needle holder to hold the knot and leave the other ear free.

13. Lift the kidney caudal pole through the abdominal incision and tie the silk suture by gently pulling the free ear until the kidney remain still (see Note 14).

14. Use a cotton-swab to dry out the renal capsule.

15. Grasp the capsule under a surgical stereoscope with fine forceps and make a 2-3 $\mathrm{mm}$ incision with Vannas spring scissors in the capsule over the lateral aspect of the kidney. 16. Create a subcapsular pocket by gently sliding back and forth straight suture tying forceps under the kidney capsule (see Note 15). Allowing the forceps to gently open when inside the capsule helps create enough space for the HIO.

17. Grab one HIO using straight suture tying forceps and insert it in the subcapsular pocket (see Note 16).

18. Cut the 7-0 silk suture and return the kidney within the abdominal cavity.

19. Flush the abdominal cavity with $2-3 \mathrm{~mL}$ of piperacillin/tazobactam solution to help prevent bacterial infection.

20. Close the incision in double layers with continuous over and over sutures using 4-0 VICRYL RAPIDE® suture (see Note 17). 
21. Allow mice to recover in a warm and dry incubator $\left(30^{\circ} \mathrm{C}\right)$ and monitor at least every 15 minutes until they resume activity and are able to maintain a sternal or sitting position. 22. After recovery, place mice back into cages with regular bedding and provided ad lib Bactrim diet and water.

23. Evaluate animals 12 hours later, and then daily throughout the remainder of the experiment. Appetite, attitude, and hydration should be noted as an indication of recovery from the surgery. Supplemental fluids or/and analgesics should be administered postoperatively as needed.

3.3 Sample collection, proliferative cell staining.

\subsubsection{Tissue preparation.}

1. Inject mice intraperitoneally with a single dose of EdU $(50 \mathrm{mg} / \mathrm{kg})$ using a sterile $27 \mathrm{G} \mathrm{x} 1 / 2$ needle attached to a 1-ml TB syringe 24 hours prior harvest (see Notes 18 and 19).

2. Sacrifice mice in accordance with the approved animal protocol in place.

3. Dissect out the kidney with the transplanted HIO (tHIO).

4. Cut the tHIO in half removing any accumulated mucous.

5. Transfer tissue into an appropriately labeled tissue processing embedding cassette.

4. Fix samples in $4 \%$ paraformaldehyde (PFA) diluted in PBS at $4{ }^{\circ} \mathrm{C}$ overnight.

5. Wash samples in PBS for 15-60 min with gentle agitation. Repeat the procedure 3 times.

6. Place samples in a tissue processor and proceed overnight to a standard tissue processing protocol:

$-70 \%$ Ethanol x 2 for 30 min each

$-75 \%$ Ethanol for $1 \mathrm{~h}$ 
$-90 \%$ Ethanol for $1 \mathrm{~h}$

$-95 \%$ Ethanol for $1 \mathrm{~h}$

$-100 \%$ Ethanol x 2 for $1 \mathrm{~h}$ each

$-100 \%$ Ethanol for $20 \mathrm{~min}$

-Xylene $\mathrm{x} 3$ for $1 \mathrm{~h}$ each

-Paraffin x 3 for $1 \mathrm{~h}$ each

7. Remove samples from tissue processor and embed them into appropriately sized disposable base molds.

8. Discard the lid of the cassette and affix the bottom portion on top of the mold creating a tissue block.

9. Remove the disposable base mold from the paraffin tissue block.

10. Section into the block slightly, exposing the desired tissue face.

11. Rehydrate the tissue soaking in a bath of PBS for $1 \mathrm{~h}$ at room temperature (RT), before chilling on ice.

12. Section the tissue into ribbons $5-\mu \mathrm{m}$ thick and float sections until wrinkles disappear in a tissue flotation bath.

13. Mount sections on to microscope slides.

14. Bake the microscope slides at $60{ }^{\circ} \mathrm{C}$ for $1 \mathrm{~h}$.

15. Store microscope slides at room temperature until further use.

3.3.2 Tissue section staining.

1. Warm microscope slides $30 \mathrm{~min}$ at $65^{\circ} \mathrm{C}$.

2. Rehydrate microscope slides by immersing them in the following series of baths:

-Xylenes x 3 for 15 min each 
$-100 \% \mathrm{EtOH} \times 2$ for 2 min each

$-95 \% \mathrm{EtOH}$ for $2 \mathrm{~min}$

$-85 \% \mathrm{EtOH}$ for $2 \mathrm{~min}$

$-70 \% \mathrm{EtOH}$ for $2 \mathrm{~min}$

-Deionized water for $5 \mathrm{~min}$

3. Perform heat induced epitope retrieval in a $\mathrm{pH} 6$ citrate buffer.

4. Permeabilize tissue sections in $0.5 \%$ Triton X-100/ PBS at room temperature for 5 min with gentle agitation.

5. Wash in PBS for 5 min with gentle agitation. Repeat the procedure 2 times.

6. Outline tissue sections with a hydrophobic pen to contain reagents.

7. Proceed to EdU Click-iT staining following manufacturer's instructions.

8. Wash slides in PBS for 15 min each with gentle agitation. Repeat the procedure 3 times.

9. Incubate slides with blocking solution for $1 \mathrm{~h}$ in a square bioassay dish lined with a damp paper towel to maintain humidity in the chamber.

10. Aspirate blocking solution. Do not wash slides.

11. Incubate slides with rabbit anti-MKI67 at [1:500] and mouse anti-CDH1 at [1:500] in antibody diluent at $4{ }^{\circ} \mathrm{C}$ overnight in humidity chamber.

12. Wash slides in PBS for 15 min each with gentle agitation (see Note 20). Repeat the procedure 3 times.

13. Incubate slides with donkey anti-rabbit Alexa Fluor 488 (binds to anti-MKI67 antibody) and donkey anti-mouse Alexa Fluor 568 (binds to anti-CDH1 antibody) at [1:1000] in antibody diluent at $4{ }^{\circ} \mathrm{C}$ overnight in a humidity chamber.

14. Wash slides in PBS for 15 min with gentle agitation while protected from light. Repeat the procedure 3 times. 
15. Incubate slides with $1 \mu \mathrm{g} / \mathrm{mL}$ of DAPI in PBS for $10 \mathrm{~min}$, or other suitable fluorescent counterstain, while protected from light.

16. Wash microscope slides in PBS for $3 \times 15$ min each, while protected from light.

17. Mount microscope slides with coverslips using 70\% glycerol in PBS, or another aqueous mounting medium.

18. Proceed to imaging and cell counting under a fluorescent microscope (Figure 1a-f).

19. Count by position recording $\mathrm{CDH} 1+/ \mathrm{MKI} 67+$ cells as positive and $\mathrm{CDH} 1+/ \mathrm{MKI} 67-$ as negative. Record with the "position 1" at the base of the crypt working your way upward to “position 20" (see Note 21).

20. Plot values as a histogram over "position 1" to "position 20"in an appropriate statistical software.

21. Apply an appropriate curve fit to the histogram (i.e. Gaussian) to visualize the zone of highest proliferation (see Note 22).

a. CDH1/MKI67/EdU/DAPI

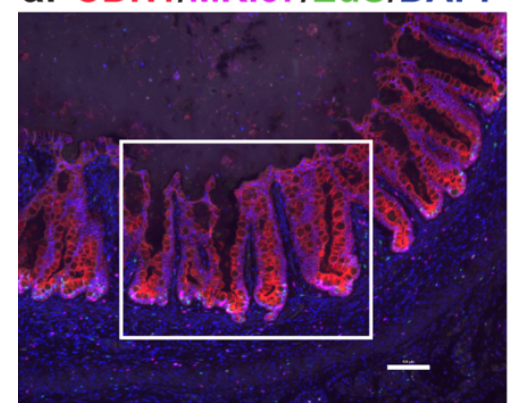

b. $\mathrm{CDH} 1 / \mathrm{MKI} 67 / \mathrm{EdU} / \mathrm{DAPI}$

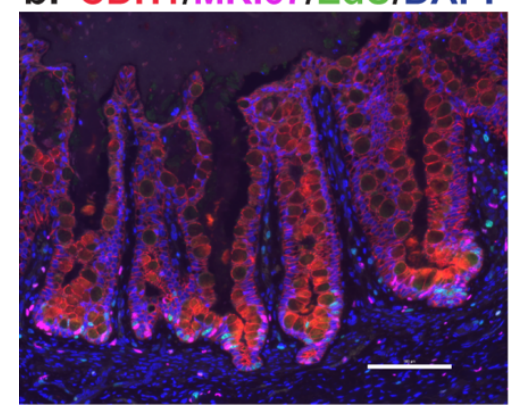

c.

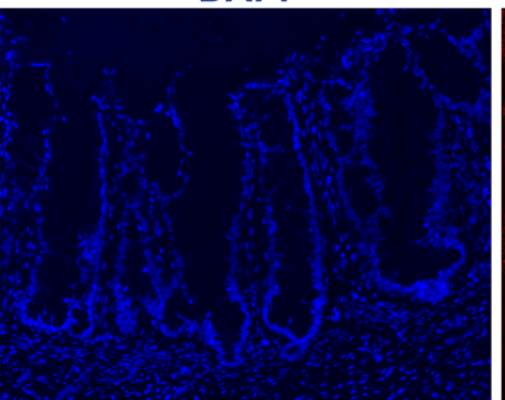

e.

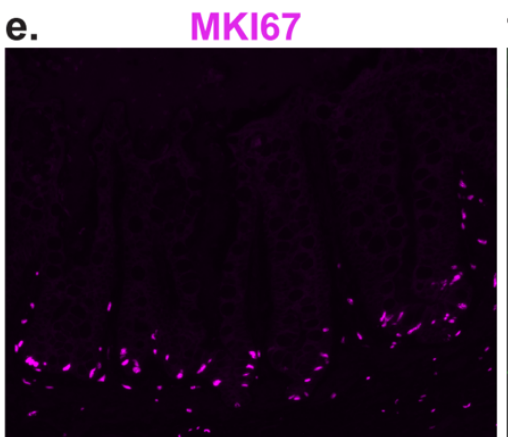

d.

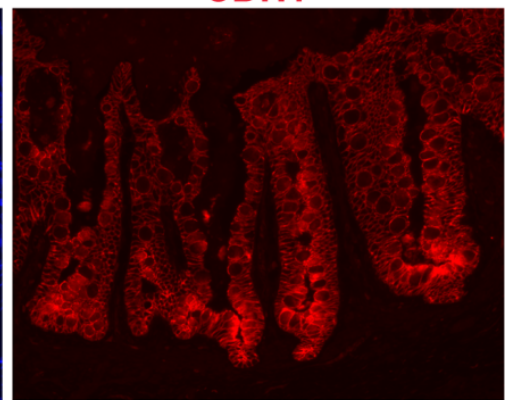

f.

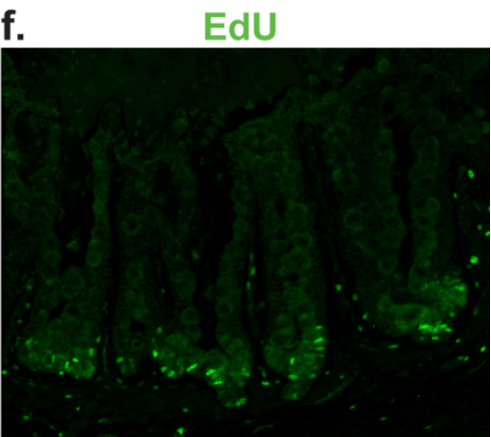

Figure 1: Intestinal cell proliferation in transplanted Human Intestinal Organoids (HIO). 
Immunofluorescence staining of tHIO at 12 weeks post transplantation at 10x (a) and 20x (b) magnification. DAPI is shown in blue (c), CDH1 in red (d), MKI67 in purple (e), and EdU staining in green (f) (All scale bars, $100 \mu \mathrm{m})$.

3.4 Isolation of tHIO intestinal crypts and culturing to generate enteroids.

1. Prepare all the reagents before the beginning of the experiment. Thaw the basement membrane matrix on ice (Figure 2a).

2. Sacrifice mice in accordance with the approved IACUC animal protocol in place (Isoflurane inhalation followed by cervical dislocation) 8 to 12 weeks post-transplantation.

3. Dissect out the tHIO from the mouse kidney.

4. Wash the dissected tHIO with ice-cold DPBS.

5. Cut the tHIO using a razor blade to expose the interior lumen (see note 23).

6. Using $0.2 \mathrm{~mm}$ diameter minutien pins, secure the piece of tissue on a silicone-coated glass Petri dish filled with ice-cold DPBS.

7. Stretch and pin the tissue flat with the mucosal side facing up (see Note 24).

8. Gently scrape the surface of the mucosa with curved forceps to remove villi and debris and any mucus that is present.

9. Wash the tissue 3-4 times with ice-cold chelation buffer to remove villi and debris (see note 25).

10. Cover the biopsy with freshly prepared 2mM EDTA chelation buffer (see Note 26).

11. Place the Petri dish on ice and shake gently for $30 \mathrm{~min}$ on a horizontal orbital shaker.

12. Wash the tissue with ice-cold chelation buffer without EDTA. Repeat the procedure 4 times and leave the tissue in ice-cold chelation buffer.

13. Process the tissue under a dissecting microscope 
14. Gently scrape the mucosal layer to release the intestinal crypts using curved forceps. (see Note 27).

15. Gently remove the crypt suspension from the petri dish using a pipette and transfer it to a $15 \mathrm{~mL}$ conical tube (see Note 28).

16. Filter the crypt suspension through a $150 \mu \mathrm{m}$ nylon mesh (see Note 29).

17. Centrifuge the crypt suspension $5 \mathrm{~min}$ at $50 \times \mathrm{g}, 4^{\circ} \mathrm{C}$ and discard the supernatant.

18. Resuspend the pellet in $1 \mathrm{~mL}$ ice-cold chelation buffer.

19. Centrifuge the crypt fraction for $10 \mathrm{~min}$ at $150 \times \mathrm{g}, 4^{\circ} \mathrm{C}$ and remove the supernatant.

20. Resuspend the crypt pellet in basement membrane matrix using pre-chilled pipet tips (200 to 500 crypts $/ 50 \mu 1$ basement membrane matrix).

21. Apply $50 \mu 1$ of crypt suspension in basement membrane matrix per well on the pre-warmed plate. Slowly eject the basement membrane matrix in the center of the well (Figure 2b-c).

22. Place the 24 -well plate in a $37^{\circ} \mathrm{C}, 5 \% \mathrm{CO} 2$ incubator for 30 min to allow a complete polymerization of the basement membrane matrix.

23. Overlay the basement membrane matrix with $500 \mu 1$ of Intesticult ${ }^{\circledR}$ Organoid Growth medium

24. Incubate the plate in a $37^{\circ} \mathrm{C}, 5 \% \mathrm{CO} 2$ incubator.

25. Replace the medium with fresh Intesticult ${ }^{\circledR}$ Human Organoid Growth medium every 2 days for 8-10 days (see Notes 30 and 31) (Figure c-e). 


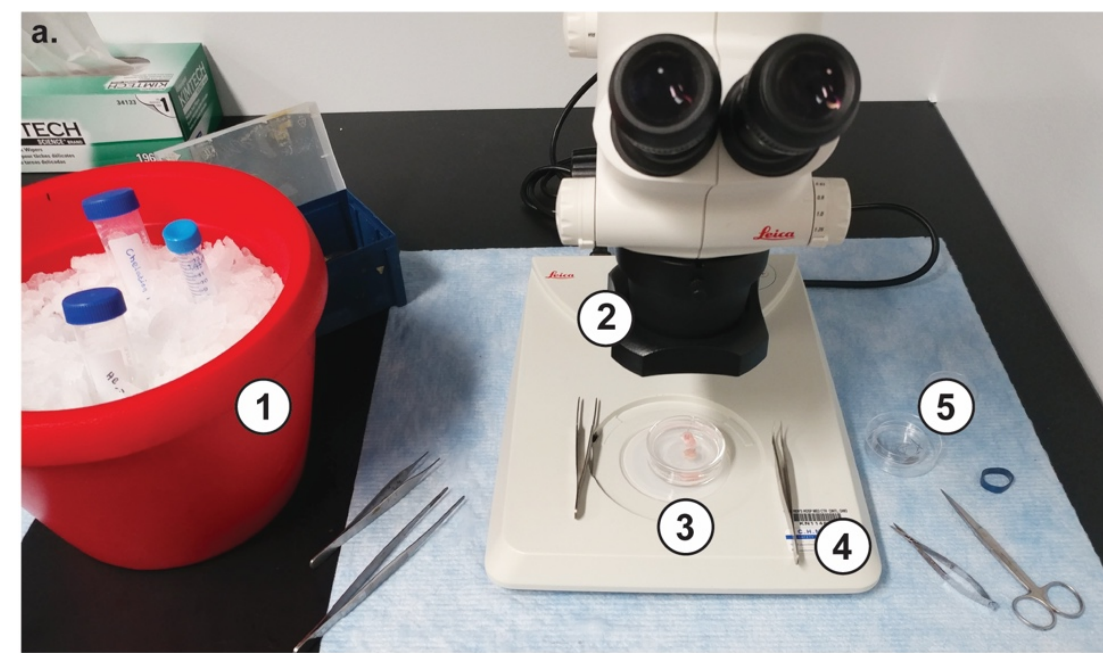

1. Buffers on ice: Chelation, HBSS, PBS

2. Dissecting microscope

3. Sylgard coated petri dish

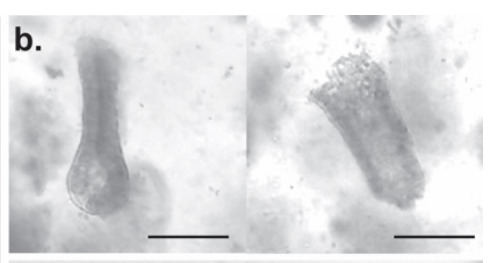

c.

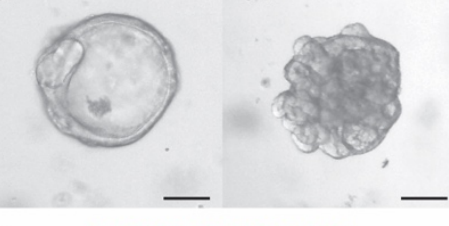

e. MKI67/CDH1/DAPI

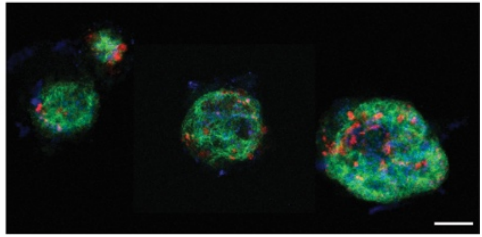

Figure 2: Enteroids derived from transplanted Human Intestinal Organoids (tHIO).

(a) Example of an experimental setup to generate tHIO-derived enteroids. (b) Close-up picture on representative tHIO crypts picked up before embedding in Matrigel ${ }^{\circledR}$. (c-d) tHIOderived enteroids in Matrigel ${ }^{\circledR}$ after 2 days in culture. (e) Immunofluorescence staining of tHIO-derived enteroids. DAPI is shown in blue, CDH1 in green, MKI67 in red (All scale bars, $50 \mu \mathrm{m})$

4. Notes.

1. Divide intestinal growth medium into $10 \mathrm{~mL}$ aliquots in $15 \mathrm{~mL}$ conical tubes and freeze at $20^{\circ} \mathrm{C}$ for up to 3 months. Store thawed aliquots up to 5 days at $4{ }^{\circ} \mathrm{C}$ without loss of activity.

2. Males are preferably used for the kidney subcapsular transplantation as their kidneys are bigger and easier to access.

3. The chow diet is supplemented with antibiotics and given to the mice at least 14 days prior any surgeries. The antibiotics decrease inflammation and risk of infection.

4. The anesthesia system delivers an isoflurane and oxygen mixture that can be controlled and monitored to maintain the anesthesia during surgery. The extra anesthetic gas is collected and evacuated into a canister. 
5. Aqueous mounting media can also be used to mount coverslips onto microscope slides.

6. Desiccated 5-ethynyl-2'-deoxyuridine (EdU) is resuspended in PBS and heated at $70^{\circ} \mathrm{C}$ for 1 minute to achieve complete powder dissolution.

7. Intestinal growth medium supplemented with $100 \mathrm{ng} / \mathrm{ml}$ recombinant Wnt3a (1:1000 dilution of $100 \mu \mathrm{g} / \mathrm{ml}$ stock), $1 \mu \mathrm{g} / \mathrm{ml} \mathrm{R}$-spondin 1 (1:1000 dilution of $1 \mathrm{mg} / \mathrm{ml}$ stock), 100 $\mathrm{ng} / \mathrm{ml}$ Noggin (1:1000 dilution of $100 \mu \mathrm{g} / \mathrm{ml}$ stock), and $50 \mathrm{ng} / \mathrm{ml}$ EGF (1:10 000 dilution of $500 \mathrm{mg} / \mathrm{ml}$ stock) can be used to culture HIO-derived epithelial organoid. Alternatively, recombinant growth factors could be replaced by Wnt3a, R-spondin, and Noggin conditioned media.

8. Intestinal growth medium aliquots are thawed and can be kept up to 5 days at $4{ }^{\circ} \mathrm{C}$ without loss of activity. Add the human recombinant EGF prior media change (1:10 000 stock dilution).

9. In our experience, HIOs can be transplanted from 20 to 40 days of culture in vitro. 10. Final anesthetic gas concentration is achieved by delivering $2 \%$ Isoflurane with $2.5-3$ $\mathrm{L} / \mathrm{min} \mathrm{O} 2$.

11. The left kidney is used for ease of access.

12. Analgesia provisions are most effective at reducing the intensity of painful stimulation when given prior to the surgery. Any animal showing evidence of pain should be provided analgesia. Other opioids like Buprenorphine can be used i.e. Butorphanol (0.2-2 mg/kg subcutaneous or intraperitoneal) or Oxymorphone $(0.2-0.5 \mathrm{mg} / \mathrm{kg}$ subcutaneous).

13. Keep the animal warm using a $37^{\circ} \mathrm{C}$ heating-pad. Adjust anesthetic gas concentration to 1.5-1.75\% Isoflurane with 2-3 L/min O2.

14. This technique allows you to hold the kidney outside the abdominal cavity. Do not completely tie the knot to avoid renal vascular ligation and permanent kidney damage. Alternatively, curved forceps can be used to lift the kidney. 
15. Slide the closed straight suture tying forceps under the capsule and open the forceps while pulling it back. Repeat the motion until appropriate size of the subcapsular pocket is achieved. 16. Inserted HIOs will not dislodge from under the subcapsular pocket.

17. VICRYL RAPIDE® sutures are synthetic coated absorbable sutures and the animals will not chew them. Alternatively, skin staplers can be used.

18. In our experience 8-12 weeks post-transplanted HIOs provide us with a fully laminated small intestinal tissue that can be further used for downstream applications ranging from physiological to molecular assays. HIOs transplanted beyond a year do not exhibit common intestinal epithelial features probably due to the accumulation of mucus and debris within the lumen.

19. Further characterization of cell cycle kinetics can be achieved by varying the duration of the EdU pulse and/or varying the duration of the chase using additional thymidine analogues i.e. CldU, IdU. For example, dual pulse chase can be achieved by injecting a single dose of EdU, followed 24 hours later by a single injection of $\operatorname{BrdU}(100 \mathrm{mg} / \mathrm{Kg})$.

20. A minimum of 15 minutes is recommended to wash the slides.

21. Count a minimum of 10 well oriented crypts per sample. Only count well oriented crypts, and consider either ascending side of the crypt, not both.

22. The means of the curve fits may be directly compared. Other more sophisticated comparisons such as an F test to compare models may also be used.

23. Make sure there is mucus present and also observe under the scope for the presence of villi.

24. If the harvested HIO has multiple cystic structures, open them up using small scissors to expose the mucosal layer.

25. If the tissue seems high in mucus content adding dithiothreitol (DTT; final concentration $0.5 \mathrm{mM})$ to the chelation buffer increases crypt yield. 
26. To prepare $2 \mathrm{mM}$ EDTA chelation buffer, add $200 \mu \mathrm{l}$ of $0.5 \mathrm{M}$ EDTA in $49.8 \mathrm{~mL}$ chelation buffer.

27. Unlike biopsies and adult human tissue, the crypts in these tissues do not have dark Paneth cells, so it may be harder to visualize them under the dissecting scope.

28. Check the tissue to make sure that almost all crypts have been removed from the mucosa.

29. Check the flow-through for crypt enrichment under an inverted microscope.

30. Enteroids can be passaged 7 to 10 days after seeding and/or frozen for long-term storage ${ }^{10}$.

31. Enteroids can be fixed using 2\% PFA and stained for immunofluorescence. 


\section{References.}

1. Barker, N. Adult intestinal stem cells: critical drivers of epithelial homeostasis and regeneration. Nat. Rev. Mol. Cell Biol. 15, 19-33 (2014).

2. Simons, B. D. \& Clevers, H. Stem cell self-renewal in intestinal crypt. Exp. Cell Res. 317, 2719-2724 (2011).

3. Noah, T. K., Donahue, B. \& Shroyer, N. F. Intestinal development and differentiation. Exp. Cell Res. 317, 2702-2710 (2011).

4. Date, S. \& Sato, T. Mini-Gut Organoids: Reconstitution of the Stem Cell Niche. Annu. Rev. Cell Dev. Biol. 31, 269-289 (2015).

5. Spence, J. R. et al. Directed differentiation of human pluripotent stem cells into intestinal tissue in vitro. Nature 470, 105-109 (2011).

6. Watson, C. L. et al. An in vivo model of human small intestine using pluripotent stem cells. Nat. Med. 20, 1310-1314 (2014).

7. McCracken, K. W., Howell, J. C., Wells, J. M. \& Spence, J. R. Generating human intestinal tissue from pluripotent stem cells in vitro. Nat. Protoc. 6, 1920-1928 (2011).

8. Múnera, J. O. \& Wells, J. M. Generation of Gastrointestinal Organoids from Human Pluripotent Stem Cells. Methods Mol. Biol. Clifton NJ 1597, 167-177 (2017).

9. Mahe, M. M., Brown, N. E., Poling, H. M. \& Helmrath, M. A. In Vivo Model of Small Intestine. Methods Mol. Biol. Clifton NJ 1597, 229-245 (2017).

10. Mahe, M. M., Sundaram, N., Watson, C. L., Shroyer, N. F. \& Helmrath, M. A. Establishment of human epithelial enteroids and colonoids from whole tissue and biopsy. J. Vis. Exp. JoVE (2015). doi:10.3791/52483 